\title{
Gastric Lavage Malignant Cells (yGL) and Hypohemoglobinemia (yAnemia) as New Systems of Tumor Regression Grading and Prognostic Prediction for Gastric Cancer After Neoadjuvant Treatment
}

\author{
EDOARDO VIRGILIO ${ }^{1}$, ENRICO GIARNIERI ${ }^{2}$, MARIA ROSARIA GIOVAGNOLI ${ }^{2}$, \\ MONICA MONTAGNINI ${ }^{2}$, ANTONELLA PROIETTI ${ }^{2}$, ROSARIA D'URSO ${ }^{2}$, ALESSANDRA FEGIZ ${ }^{1}$, \\ PAOLO MERCANTINI ${ }^{1}$, GENOVEFFA BALDUCCI ${ }^{1}$ and MARCO CAVALLINI ${ }^{1}$
}

${ }^{1}$ Department of Medical and Surgical Sciences and Translational Medicine, Faculty of Medicine and Psychology;

${ }^{2}$ Department of Clinical and Molecular Medicine, Faculty of Medicine and Psychology,

University "Sapienza", St. Andrea Hospital, Rome, Italy

\begin{abstract}
Background/Aim: Although reckoned necessary for survival benefit, neoadjuvant chemotherapy (NAC) of gastric cancer $(G C)$ patients has so far provided questionable results. Consequently, searching for new and clearer systems of response to NAC, post-NAC re-evaluation and prognostic prediction appears essential. The purpose of this study was to examine endogastric cytopathology and hemoglobin level count as new features, potentially useful for GC patients after NAC. Patients and Methods: Between April 2012 and October 2018, 21 of 116 patients with resectable $G C$ received NAC and were investigated for the presence of free-floating malignant cells in their gastric lavage (yGL1) and the development of hypohemoglobinia (yAnemia). Results: $y G L 1$ and yAnemia were found in 11 and 12 patients, respectively. $y G L 1$ correlated with the traditional parameters of tumor regression $(p=0.0424)$. Both $y G L 1$ and yAnemia were found to be independent predictive factors of overall and progression-free survival ( $p \leq 0.0364)$. Conclusion: In the light of our results, the yGL1 and yAnemia appear two promising, simple and interesting clinicopathological features which should always be examined for better clarifying GC patients' response to NAC.
\end{abstract}

Correspondence to: Prof. Edoardo Virgilio, Medical and Surgical Sciences and Translational Medicine, Faculty of Medicine and Psychology, University "Sapienza", St. Andrea Hospital, via di Grottarossa 1035-39, 00189, Rome, Italy. Tel: +390633775693, Fax: +39 0633775322, e-mail: aresedo1992@yahoo.it, edoardo.virgilio@uniroma1.it

Key Words: Neoadjuvant chemotherapy, gastric cancer, gastric lavage, neoadjuvant treatment, neoadjuvant radiotherapy, oncology, cytopathology.
Despite continuous decrease and effort in screening and faster diagnosis, according to the latest estimates on incidence and mortality provided by the International Agency for Research on Cancer (IARC), gastric carcinoma (GC) (including cardia and non-cardia tumors) maintains a predominant position worldwide; in fact, in both sexes combined, it is responsible for over 1 million new cases in 2018 and an estimated 783,000 deaths, making it the fifth most frequently diagnosed cancer (after lung, female breast, prostate and colorectal cancer) and the third leading cause of neoplastic mortality (after lung and colorectal cancer) (1). Differing from other gastrointestinal malignancies where multistep carcinogenesis is well-recognized (as for colorectal cancer), to date sporadic GC still has a less known and understood pathobiology (2-6).

Surgery still represents the mainstay of therapy but, except for early-stage disease (including early GC; EGC), it cannot assure an effective long-term recovery and must be conducted in concert with peri-operative treatment (7-11). Neoadjuvant chemotherapy (NAC), however, despite initial enthusiasm, has sooner showed conflicting results and limitations against this type of cancer (including gastric and junctional lesions) especially in terms of survival (12-16).

To clarify these doubts, ascertain its role and, consequently, optimize the management of GC patients, recently evaluation of NAC effectiveness has been addressed with several new systems and markers, both theoretical and practical (15-18). With this purpose, in our study GC patients submitted to NAC were investigated regarding the presence of free malignant cells in their gastric lavage and the development of hypohemoglobinemia, hereinafter referred as yGL and yAnemia, respectively. Our results suggest that investigation of these two parameters could be useful for evaluating response to NAC in GC patients. 


\section{Materials and Methods}

Patients. Between April 2012 and October 2018, the yGL samples obtained from $116 \mathrm{GC}$ patients with staging and prognostic intent were prospectively analyzed. Enrolment was performed according to the ethical standards written in the Declaration of Helsinki. Informed consent was obtained from all participants during their stay at the Division of General and Emergency Surgery of St. Andrea Hospital, Faculty of Medicine and Psychology, Sapienza University, Rome, Italy. The procedure, cytomolecular analysis and pathoprognostic significance of GL and yGL in GC patients have already been investigated as previously described (19-23). In particular, yGL was collected from all patients prior to surgery and tumor manipulation. After completion of neoadjuvant treatment (NAT) including NAC alone, neoadjuvant radiotherapy (NAR) alone, or both), but before surgical act, routine blood tests were ordered for each patient; anemia (yAnemia) was diagnosed with hemoglobin $(\mathrm{Hgb})$ levels below $13.5 \mathrm{~g} / \mathrm{dl}$ for men and $12 \mathrm{~g} / \mathrm{dl}$ for women, as universally acknowledged (24). Traditional methods for evaluating the therapeutic response to NAT included clinicolaboratory tests (endoscopy and serum markers such as CEA, Ca 19.9 and Ca 72.4), radiology (contrast-enhanced computed and positron emission tomography) and histology through the 4-tiered tumor regression grading system (TRG) as developed by Becker and colleagues (25). Post-NAT pathology of surgical specimens was described following the 7th and 8th edition of AJCC TNM Staging System $(26,27)$. Patients were followed-up from hospital discharge until December 2018.

Statistical analysis. Statistical analysis was performed using MedCalc Statistical Software version 18.11 (MedCalc Software bvba, Ostend, Belgium). Categorical variables were compared using the Chi-square test, whereas continuous data were compared through the Student's $t$-test. Four types of survival were investigated: median overall survival rate (OS), defined as the time from GL collection to death from any cause, progression-free survival (PFS) as the time elapsed between GL retrieval and metastatic tumor progression -but not local or regional progression- or death from any cause, diseasefree survival (DFS) or recurrence-free survival (RFS), as the span of life between GL and any recurrence (local or regional), distant metastasis or death due to any cause and, eventually, time to tumor progression (TTP) which differs from PFS by including only cancerrelated death $(28,29)$. All the survival curves were performed in accordance with the Kaplan-Meier method and the log-rank test was used to evaluate statistical significance. Comparison among yGL, yAnemia and the traditional clinico-radio-histologic methods evaluating NAC response (which, hereafter, will be abbreviated as $\mathrm{yCRH}$ ) were performed in terms of OS using a logistic regression tool. Univariate and multivariate analyses were adopted (with oneway or two-way ANOVA test and Cox proportional hazards model, respectively) to assess significant association and independency, respectively, among predictive factors. A $p$-value $\leq 0.05$ was considered statistically significant.

\section{Results}

Traditional peri-operative clinicopathological parameters. Only 21 of 116 GC patients received NAT before curative surgery and have been accordingly included in this study; the other 95 were excluded. Their major clinicopathological characteristics are summarized in Table I. Male-to-female ratio was 2.5:1, average age 64.3 years. Fifteen tumors were proximal (at gastric cardia, fundus, and corpus), only 6 distal (at antrum and pylorus). According to Siewert classification, 6 cancers were type 1, 3 type 2, and 4 type 3 . Eighteen patients were given NAC alone, other 3 combined NACNAR. Fluorouracil (5FU), including its oral form capecitabine (XEL), was the chemotherapy agent most frequently adopted (100\% of patients), followed by platinum (PL) (19 cases); PL-5FU association was given in 17 patients. Epirubicin-cisplatin-5FU was the regimen most frequently used (7 patients), followed by epirubicinoxaliplatin-XEL (4 participants) and FOLFOX (leucovorin, oxaliplatin, and 5FU). As for CRH response to NAT, only 6 patients ameliorated, while 4 aggravated, and 11 showed stable disease. At Chi-square test, proximal tumor site associated well with NAC ( $p=0.0495), 5-\mathrm{FU}(p=0.0495$ as well), and PL-based regimen $(p=0.0002)$. Fourteen $(66.7 \%)$ cancers resulted locally advanced (stage yIII and yIV) and required open total gastrectomy in $71.4 \%$ of cases taking a mean operative time of $245.3 \mathrm{~min}$ and an average number of 24.5 loco-regional lymph nodes (Table I). Rates of early postoperative morbidity and peri-operative mortality were $28.6 \%$ and $19 \%$, respectively, necessitating re-hospitalization for one patient and emerging re-surgery in 3 cases. Eleven patients went through adjuvant treatment. Interestingly, among the 4 EGCs, 3 were yGL1 and 2 of these have died within the end of this study (30).

The yGL parameter. At cytopathological analysis, free malignant cells were found in 11 GL samples (yGL1 cases), whereas no cell was seen in other 10 (yGL0 samples) (Table I). yGL1 was significantly associated with poorer OS $(p=0.0431)$ at Chi-square test (Table II). In particular, at a median follow-up of 14.5 months (range=1-66), 10 of 15 GC patients who died were yGL1. Moreover, associations of yGL1with AT (including both AC and AR) $p=0.0489$ ), AC alone $(p=0.0489)$, and combined AC-AR $(p=0.0207)$ were also statistically significant. This finding is probably explained by the fact that most aggressive cancers, which were yGL1, necessitated AT as further treatment (Table II). More specifically, in comparison with yCRH and yAnemia, yGL achieved significant results in terms of OS at logistic regression analysis ( $p=0.0424$ with an overall model fit of $p=0.0391$ ). In detail, the 3 of the $6 \mathrm{GC}$ patients showing yCRH amelioration were yGL1 and 2 of these have died at the aforementioned median OS; on the other hand, also 2 of the 3 yGL0 with yCRH amelioration have died. Concerning the 15 patients with stable or worsening yCRH, 8 were yGL 1 and 7 yGL0; out of these patients, 8 and 4, respectively, died. The Kaplan-Meier model showed that yGL1 patients had shorter OS compared to yGL0 counterpart (13 vs. 33 months, respectively) and this finding achieved a customary level of 
Table I. Main clinicopathological features of the 21 gastric cancer $(G C)$ patients treated with neoadjuvant treatment followed by curative surgery and adjuvant therapy.

\begin{tabular}{|c|c|}
\hline Gender & $\begin{array}{l}\text { Male: } 15 \\
\text { Female: } 6\end{array}$ \\
\hline Race & Caucasian: 20 \\
\hline & Latino American: 1 \\
\hline Age (mean) & $\begin{array}{c}64.3 \text { years } \\
(\text { range }=41-83)\end{array}$ \\
\hline Severe comorbidities & $\begin{array}{l}\text { Presence: } 8 \\
\text { Absence: } 13\end{array}$ \\
\hline Tumor site & $\begin{array}{l}\text { Proximal*: } 15 \\
\text { Distal*: } 6\end{array}$ \\
\hline Siewert type & $\begin{array}{c}\text { Type } 1 \text { and } 2: 9 \\
\text { Type } 3 \text { and non-Siewert cancers: } 12\end{array}$ \\
\hline NAT & $\begin{array}{c}\text { NAC alone: } 18 \\
\text { NAC-NAR combined: } 3\end{array}$ \\
\hline NAC regimen & $\begin{array}{c}\text { ECF: } 7 \\
\text { EOX: } 4 \\
\text { FOLFOX: } 2 \\
\text { PL and 5-FU/XEL-based: } 17 \\
\text { PL-based: } 19 \\
\text { 5-FU/XEL-based: } 21\end{array}$ \\
\hline $\begin{array}{l}\text { Clinico-radio-histologic } \\
\text { response }(\mathrm{CRH}) \text { to NAT }\end{array}$ & $\begin{array}{c}\text { Amelioration: } 6 \\
\text { Stability or worsening: } 15\end{array}$ \\
\hline ASA class & $\begin{array}{c}1-2: 7 \\
3-6: 14\end{array}$ \\
\hline yGL & $\begin{array}{l}\text { GL0: } 10 \\
\text { GL1: } 11\end{array}$ \\
\hline yAnemia & $\begin{array}{l}\text { Development: } 12 \\
\text { Absence: } 9\end{array}$ \\
\hline ypT & $\begin{array}{c}\text { T1a: } 1 \\
\text { T1b: } 3 \\
\text { EGC (T1a }+ \text { T1b): } 4 \\
\text { T1-T2: } 5 \\
\text { T3-T4: } 16\end{array}$ \\
\hline ypN & $\begin{array}{c}\text { N0: } 4 \\
\text { N1-3: } 17\end{array}$ \\
\hline урм & $\begin{array}{l}\text { M0: } 17 \\
\text { M1: } 4\end{array}$ \\
\hline yStage & $\begin{array}{c}1: 5 \\
2-4: 16\end{array}$ \\
\hline G & $\begin{aligned} \text { G1 } & : 3 \\
\text { G2- } 4: & 18\end{aligned}$ \\
\hline
\end{tabular}

statistical significance $(p=0.0223$ ) (Figure 1). At univariate analysis, there was a strong relationship of yGL1 with OS $(p=0.040$ at one-way ANOVA) and yAnemia $(p=0.0045$ at two-way ANOVA) (Table III). Furthermore, multivariate analysis demonstrated yGL to be an independent predictive factor of OS $(p=0.0331$ with an overall fit of $p=0.0014$, Table IV), PFS, and DFS (for each endpoint $p=0.0289$ with an overall model fit of $p=0.0009$, Table V).

The yAnemia parameter. Following NAT but before surgery, 12 patients developed yAnemia, whereas Hgb levels were

\begin{tabular}{|c|c|}
\hline Lauren classification & $\begin{array}{c}\text { Intestinal type: } 9 \\
\text { Non-intestinal type: } 12\end{array}$ \\
\hline 2010 WHO classification & $\begin{array}{l}\text { Tubular type: } 10 \\
\text { Non-tubular type: } 11\end{array}$ \\
\hline Signet ring cells & $\begin{array}{l}\text { Presence: } 2 \\
\text { Absence: } 19\end{array}$ \\
\hline LVI & $\begin{array}{l}\text { LVI0: } 7 \\
\text { LVI1: } 14\end{array}$ \\
\hline PnI & $\begin{array}{l}\text { PnI0: } 15 \\
\text { PnI1: } 6\end{array}$ \\
\hline LNR & $\begin{aligned} 0: 4 \\
>0: 17\end{aligned}$ \\
\hline $\begin{array}{l}\text { Number of sampled } \\
\text { lymph nodes (mean) }\end{array}$ & $24.5($ range $=7-62)$ \\
\hline Gastrectomy type & $\begin{array}{l}\text { Distal: } 6 \\
\text { Total: } 15\end{array}$ \\
\hline Operative time (mean) & $245.3 \min ($ range $=155-405)$ \\
\hline PLS (mean) & 14.8 days $($ range $=7-52$ ) \\
\hline 30-day postoperative complications & $\begin{array}{c}\text { Occurrence: } 6 \\
\text { Absence: } 15\end{array}$ \\
\hline 90-day postoperative complications & $\begin{array}{l}\text { Occurrence: } 1 \\
\text { Absence: } 20\end{array}$ \\
\hline Re-surgery & $\begin{array}{l}\text { Accomplishment: } 3 \\
\text { Unnecessity: } 18\end{array}$ \\
\hline Re-hospitalization & $\begin{array}{c}\text { Necessity: } 1 \\
\text { Unnecessity: } 20\end{array}$ \\
\hline $\begin{array}{l}\text { Peri-operative mortality } \\
\text { AT }\end{array}$ & $\begin{array}{c}\text { Occurrence: } 4 \\
\text { AC alone: } 5 \\
\text { AC-AR combined: } 6\end{array}$ \\
\hline
\end{tabular}

*Distal site include antro-pyloric cancers; proximal site include cardiofundic and gastric body carcinomas; NAT, neoadjuvant treatment; NAC, neoadjuvant chemotherapy; NAR, neoadjuvant radiotherapy; ECF, epirubicin, cisplatin and 5-FU; EOX, epirubicin, oxaliplatin and XEL; FOLFOX, leucovorin, 5-FU and oxaliplatin; PL, platinum; 5- FU, 5-fluorouracil; XEL, xeloda; ASA, American Society of Anesthesiologists Classification; LVI, lymphovascular invasion; PnI, peri-neural invasion; LNR, metastatic lymph node ratio; PLS, postoperative length of stay; AT, adjuvant treatment; AC, adjuvant chemotherapy; AR, adjuvant radiotherapy.

normal in 9 cases (Table I). No significant association of yAnemia with the traditional parameters for NAT response evaluation (indexed in Table I) was shown by chi-square test. Moreover, contrarily to the yGL, no association was shown between yAnemia and $\mathrm{yCRH}$, in terms of OS, at logistic regression analysis $(p=0.2279$ with an overall model fit of $p=0.0391$ ). On the other hand, as mentioned above, univariate analysis revealed that yGL1 was a significant predictive factor for yAnemia ( $p=0.0045$ at two-way ANOVA) (Table III); in particular, $5(45.45 \%)$ of the 11 yGL1 patients presented yAnemia as well. Moreover, Kaplan-Meier analysis showed 
Table II. Correlation of the presence of free-floating tumor cells in gastric lavage fluid (yGL1) with the traditional clinicopathological features of gastric cancer.

\begin{tabular}{lc}
\hline OS & $\boldsymbol{p}=\mathbf{0 . 0 4 3 1}$ \\
AT & $\boldsymbol{p = 0 . 0 4 8 9}$ \\
AC alone & $\boldsymbol{p = 0 . 0 4 8 9}$ \\
AC-RT & $\boldsymbol{p = 0 . 0 2 0 7}$ \\
All the other parameters listed in Table I & $p>0.05$ \\
\hline
\end{tabular}

OS, Overall survival; AT, adjuvant treatment (both AC and AR); AC, adjuvant chemotherapy; AC-RT, adjuvant chemo-radiotherapy. $p$-Values shown in bold are statistically significant $(p \leq 0.05)$.

Table III. Univariate analysis of free-floating tumor cells of gastric lavage fluid (yGL1) as a predictive factor for overall survival (OS) and post-neoadjuvant treatment anemia (yAnemia).

\begin{tabular}{lc}
\hline OS & $\boldsymbol{p = 0 . 0 4 0}$ (one-way ANOVA) \\
yAnemia & $\boldsymbol{p = 0 . 0 0 4 5}$ (two-way ANOVA) \\
All the other parameters & $p>0.05$ (one- and two-way ANOVA) \\
listed in Table I &
\end{tabular}

$p$-Values shown in bold are statistically significant $(p \leq 0.05)$.

significant differences of OS, PFS, DFS, and TTP between yAnemia and yHgb normal count group (Figure 2). In fact, yAnemia patients had shorter OS than those with normal $\mathrm{Hgb}$ levels ( $8.7 v s .28$ months, $p=0.0379)$, as well as poorer PFSDFS (8.7 vs. 28 months, $p=0.0230)$ and TTP (11.6 vs. 31.3 months, $p=0.0370$ ). Furthermore, at multivariate analysis, yAnemia resulted as an independent predictive factor of OS ( $p=0.0364$ with an overall fit of $p=0.0014$, Table IV), PFS and DFS (for each endpoint $p=0.0239$ with an overall model fit of $p=0.0009$, Table V).

\section{Discussion}

NAC of GC represents an important but complex topic. Given the promising but not satisfactory results of adjuvant therapy, in the last decade NAC has been adopted worldwide for its theoretical potential to shrink tumor volume, increase the rate of tumor-free surgical margins, and to destroy microscopic disease that is already present at distant sites (12). Such a successful spread followed the publication of 2 famous randomized controlled trials (RCTs) on GC NAC, the MAGIC and FNCLCC-FFCD trials $(9,10)$. Upon initial appraisal, both studies showed a survival advantage of patients treated with NAC plus curative surgery, compared to surgery alone. However, a closer examination of patients' enrolment and assignation demonstrated a heterogeneity of primary site location ( $75 \%$ GCs, $25 \%$ between lower esophagus and junctional cancers), a greater proportion on

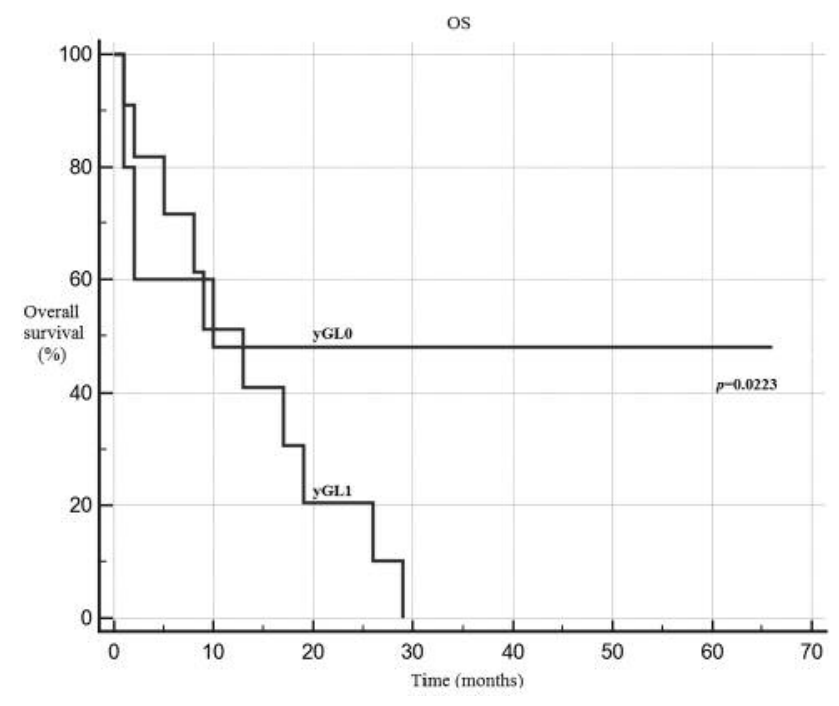

Figure 1. The Kaplan-Meier method demonstrated different overall survival (OS) between patients with (yGL1) and without (yGLO) freefloating tumor cells in their gastric lavage fluid.

initial cancers in the NAC-surgery leg compared to surgery alone, and a low percentage (42\%) of adequate lymph node dissection (D2 lymphadenectomy) in surgery alone group, in MAGIC study. In FNCLCC-FFCD study, only $25 \%$ of patients had a tumor located in the stomach (64\% junctional and $11 \%$ lower esophagus cancers) and results from D2 dissection performed in both arms were not provided $(9,10)$. Finally, the survival benefit resulted stronger for lower esophagus and gastroesophageal (MAGIC trial) or gastroesophageal cancers only (FNCLCC-FFCD trial) rather than the proper GCs (12). In the light of the reported data, it appears evident that adoption of NAC for GC has been introduced without a clear and evidence-based medicinerelated demonstration (12). Furthermore, the disadvantage of NAC for GC may be over-diagnosis; in the MAGIC trial, in fact, the target patients had clinical stage II disease, but all patients had clinical T2 tumors (14). Moreover, the present prospective study on a small number of patients also included both junctional and proper gastric lesions. As a consequence, further RCTs with a more precise GC patient selection are required to assess the efficacy of NAC in this type of malignancy. Besides, there is also the need for new systems to determine the real efficacy of NAC. The current yCRH parameters (such as serum tumor antigens, histologic TRG, RECIST criteria of conventional image studies, PERCIST criteria from functional imaging, repeat staging laparoscopy) undoubtedly help compare initial with post-treatment patients' disease $(15,25)$. However, since these parameters focus on a specific field of investigation, they do not offer a global appraisal of patient condition. In this manner, when they provide contradictory results, evaluation of the treated 

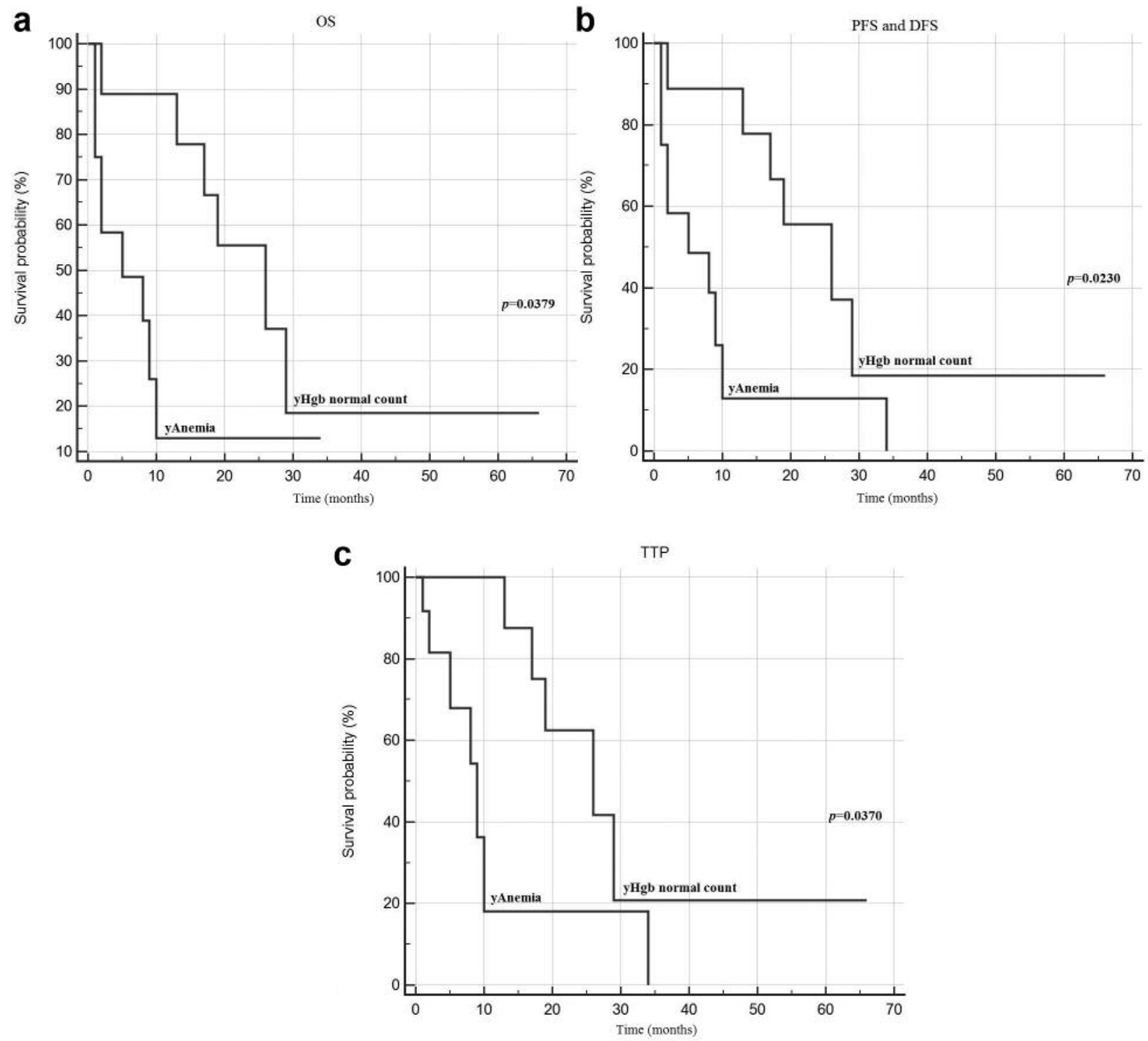

Figure 2. Kaplan-Meier curves illustrating different overall survival (OS) (A), progression-free survival (PFS) / disease-free survival (DFS) (B) and time to tumor progression (TTP) (C) for gastric cancer $(G C)$ patients who showed deficiency (yAnemia) or physiological levels of hemoglobin (yHgb normal count) after neoadjuvant treatment.

patients becomes more complicated and creates confusion even for prognostic prediction (31-36). With this regard, several reliable tissue and serum markers have already been identified, or are still under investigation, as predictors of the response of GC patients to NAC $(13,16-18,37-40)$. In our study we suggest 2 further pertinent tests for post-NAC reassessment and prognostic prediction of patients with resectable GC: the yGL and yAnemia clinicopathological features. As previously demonstrated, GL represents an excellent source of GC cytologic and molecular biomarkers (such as free malignant cells, microRNAs and long noncoding RNAs) because these are directly released by the tumor without being eliminated by the liver (41). Moreover, yGL cytomolecular analysis has provided interesting results in terms of classification, staging, screening and prognosis of this cancer (42-44). As shown in our study, the yGL status also appears to be an important and useful parameter to be applied to the clinicopathologic re-appraisal of GC patients following NAC. In fact, at univariate analysis, yGL1 statistically correlated with OS and yAnemia (Table III) and, moreover, at multivariate analysis it resulted an independent predictive factor of OS (Table IV), PFS and DFS (Table V). Interestingly, logistic regression analysis showed that yGL could also be adopted as an auxiliary system of TRG and post-NAC re- 
Table IV. Multivariate analysis of predictive factors for overall survival (OS).

\begin{tabular}{|c|c|c|c|c|c|c|}
\hline Independent variables & $\mathrm{b}$ & $\mathrm{SE}$ & Wald & $p$-Value & $\operatorname{Exp}(b)$ & $95 \%$ CI of $\operatorname{EXp}(b)$ \\
\hline yGL & 3.9899 & 1.8724 & 4.5410 & 0.0331 & 54.0514 & $1.3773-2121.2673$ \\
\hline yAnemia & 3.5728 & 1.7077 & 4.3775 & 0.0364 & 35.6175 & $1.2534-1012.1625$ \\
\hline Response to NAT & 0.7324 & 2.0480 & 0.1279 & 0.7206 & 2.0801 & $0.0376-115.1763$ \\
\hline PL-5FU-based NAC & -3.2553 & 3.1549 & 1.0647 & 0.3022 & 0.0386 & $0.0001-18.6959$ \\
\hline AT & -2.4976 & 4.2078 & 0.3523 & 0.5528 & 0.0823 & $0.0000-314.1089$ \\
\hline Re-hospitalization & 4.9843 & 3.4080 & 2.1390 & 0.1436 & 146.1027 & $0.1835-116309.7658$ \\
\hline Re-surgery & 4.7664 & 5.0731 & 0.8828 & 0.3474 & 117.5005 & $0.0056-2445258.7179$ \\
\hline Operation time & 0.0314 & 0.0227 & 1.9185 & 0.1660 & 1.0319 & $0.9871-1.0787$ \\
\hline PLS & -0.0097 & 0.0588 & 0.0274 & 0.8685 & 0.9903 & $0.8824-1.1114$ \\
\hline yR & 7.3884 & 3.0008 & 6.0620 & 0.0138 & 1617.0924 & $4.5121-579546.0347$ \\
\hline yM & -1.8734 & 1.8575 & 1.0171 & 0.3132 & 0.1536 & $0.0040-5.8554$ \\
\hline yStage & 0.2678 & 2.3556 & 0.0129 & 0.9095 & 1.3070 & $0.0129-132.2497$ \\
\hline
\end{tabular}

Overall model fit: $p=0.0014$

b, Regression coefficient beta; SE, standard error; Wald, b/SE2; Exp(b), equals e to the power of each beta value; CI, confidence interval; yGL, presence of free malignant cells in gastric lavage fluid after NAT (or NAC alone); NAT, neoadjuvant treatment; PL-5FU, platinum-fluorouracil; NAC, neoadjuvant chemotherapy; PLS, postoperative length of stay; yR, status of surgical margins after NAT (or NAC alone); yM, distant metastases after NAT (or NAC alone). $p$-Values written in bold are statistically significant $(p \leq 0.05)$.

Table V. Multivariate analysis of predictive factors for progression-free survival (PFS) and disease-free survival (DFS).

\begin{tabular}{|c|c|c|c|c|c|c|}
\hline Independent variables & $\mathrm{B}$ & SE & Wald & $p$-Value & $\operatorname{Exp}(b)$ & $95 \% \mathrm{CI}$ of $\mathrm{EXp}(\mathrm{b})$ \\
\hline yGL & 4.1291 & 1.8903 & 4.7716 & 0.0289 & 62.1235 & $1.5284-2525.1439$ \\
\hline yAnemia & 3.7679 & 1.6679 & 5.1033 & 0.0239 & 43.2911 & $1.6467-1138.0858$ \\
\hline Response to NAT & 0.6542 & 2.0473 & 0.1021 & 0.7493 & 1.9237 & $0.0348-106.3753$ \\
\hline PL-F based NAC & -3.0438 & 3.1266 & 0.9477 & 0.3303 & 0.0477 & $0.0001-21.8523$ \\
\hline AT & -2.2976 & 4.1623 & 0.3047 & 0.5809 & 0.1005 & $0.0000-350.9034$ \\
\hline Re-hospitalization & 5.0883 & 3.3875 & 2.2563 & 0.1331 & 162.1141 & $0.2120-123967.9200$ \\
\hline Re-surgery & 4.4407 & 4.9935 & 0.7908 & 0.3738 & 84.8354 & $0.0048-1510647.4292$ \\
\hline Operation time & 0.0323 & 0.0226 & 2.0354 & 0.1537 & 1.0328 & $0.9880-1.0796$ \\
\hline PLS & -0.0068 & 0.0585 & 0.0136 & 0.9070 & 0.9932 & $0.8856-1.1138$ \\
\hline$y R$ & 7.4337 & 2.9825 & 6.2123 & 0.0127 & 1692.1010 & $4.8942-585025.8296$ \\
\hline yM & -1.9559 & 1.8792 & 1.0833 & 0.2980 & 0.1414 & $0.0036-5.6260$ \\
\hline ySTage & 0.2856 & 2.3750 & 0.0145 & 0.9043 & 1.3306 & $0.0127-139.8511$ \\
\hline
\end{tabular}

Overall model fit: $p=0.0009$

$\mathrm{b}$, The regression coefficient beta; SE, standard error; Wald, b/SE2; $\operatorname{Exp}(\mathrm{b})$, equals e to the power of each beta value; CI, confidence interval. $p$-Values written in bold are statistically significant $(\leq 0.05)$.

evaluation. Concerning hypohemoglobinemia, most previous studies dealt with pre-NAC, pre- or post-surgery anemia: such a feature often correlated with histologic TRG and was demonstrated as an important predictor of postoperative survival for GC patients (45-47). Conversely, post-NAC Hgt levels as pathoprognostic factor (yAnemia) have been rarely investigated $(48,49)$. In our study, yAnemia patients had significantly shorter OS, PFS-DFS, and TTP, compared to those with normal $\mathrm{Hgb}$ count (Figure 1). Furthermore, at multivariate analysis, this category was an independent predictive factor of OS (Table IV), and PFS-DFS (Table V).

\section{Conclusion}

The yGL and yAnemia, two non-conventional markers, can help optimize re-evaluation and prognostic prediction of patients with resectable GC submitted to NAC. In fact, yGL1 as well as yAnemia were associated with a poorer survival. More specifically, both markers were shown as independent predictive factors of poor OS, PFS and DFS (Table V). Despite its limitations, our study is the first to provide significant evidence about the application of yGL and yAnemia paramenters in the prognosis of GC patients after NAC. Future 
studies are warranted to evaluate yGL and yAnemia in larger cohorts of GC patients, investigating both pre-NAT/preoperative and post-NAT/post-operative disease and preferably distinguishing junctional from proper gastric lesions.

\section{Conflicts of Interest}

The Authors declare no conflicts of interest.

\section{Authors' Contributions}

All the Authors agreed with the content of the article. Dr. Virgilio conceived of the presented research. Dr. Virgilio, Dr. Fegiz and Dr. Mercantini performed the clinical part of the research. Dr. Giarnieri, Mrs. Montagnini and Prof. Giovagnoli performed the cytopathological analysis. Dr. Proietti and Dr. D'Urso contributed to the interpretation of the results. Dr. Virgilio wrote the manuscript and performed the statistical analyses. Dr. Balducci and Dr. Cavallini helped supervise the entire project.

\section{References}

1 Bray F, Ferlay J, Soerjomataram I, Siegel RL, Torre LA and Jemal A: Cancer Statistics 2018: GLOBOCAN estimates of incidence and mortality worldwide for 36 cancers in 185 countries. CA Cancer J Clin 68: 394-424, 2018. PMID: 30207593 doi: 10.3322/caac. 21492

2 Hudler P: Challenges of deciphering gastric cancer heterogeneity. World J Gastroenterol 21: 10510-10527, 2015. PMID: 26457012 doi: 10.3748/wjg.v21.i37.10510

3 Kawakubo E, Matsumoto T, Yoshiya K, Yamashita S, Jogo T, Saeki H, Oki E, Furuyama T, Oda Y and Maehara Y: BUBR1 insufficiency is correlated with eNOS reduction experimentally in vitro and in vivo, and in gastric cancer tissue. Anticancer Res 39: 6099-6106, 2018. PMID: 30396924 doi: 10.21873/ anticanres. 12960

4 Yang E, Cai J, Zhang H, Wang G and Jiang W: Effects of lidocaine and ropivacaine on gastrc cancer cells through downregulation of ERK1/2 phosphorylation in vitro. Anticancer Res 38: 6729-6735, 2018. PMID: 3050583 doi: 10.21873/ anticanres. 13042

5 Ferri M, Lorenzon L, Onelli MR, La Torre M, Mercantini P, Virgilio E, Balducci G, Ruco L, Ziparo V and Pilozzi E: Lymph node ratio is a strong prognostic factor than microsatellite instability in colorectal cancer patients: results from a 7 years follow-up study. Int J Surg 11: 1016-1021, 2013. PMID: 23747976 doi: 10.1016/j.ijsu.2013.05.031

6 Pilozzi E, Ferri M, Onelli MR, Mercantini P, Corigliano N, Duranti E, Dionisi L, Felicioni F, Virgilio E, Ziparo V and Ruco L: Prognostic significante of $18 \mathrm{q} \mathrm{LOH}$ in sporadic colorectal carcinoma. Am Surg 77: 38-43, 2011. PMID: 21396303

7 Japanese Gastric Cancer Association. Japanese gastric cancer treatment guidelines 2014 (ver. 4). Gastric Cancer 20: 1-19, 2017. PMID: 27342689 doi: 10.1007/s10120-016-0622-4

8 Virgilio E, Balducci G, Mercantini P, Ferri M, Bocchetti T, Caterino S, Salvi PF, Ziparo V and Cavallini M: Reconstruction after distal gastrectomy for gastric cancer: Billroth 2 or Rouxen-Y procedure? Anticancer Res 37: 5595-5602, 2017. PMID: 28982875 doi: 10.21873/anticanres.11993
9 Cunningham D, Allum WH, Stenning SP, Thompson JN, Van de Velde CJ, Nicolson M, Scarffe JH, Lofts FJ, Flk SJ, Iveson TJ, Smith DB, Langley RE, Verma M, Weeden S, Chua YJ and MAGIC Trial Participants: Perioperative chemotherapy versus surgery alone for resectable gastroesophageal cancer. N Engl J Med 355: 11-20, 2006. PMID: 16822992 doi: 10.1056/ NEJMoa055531

10 Yehou M, Boige V, Pignon JP, Conroy T, Bouchè O, Lebreton G, Ducourtieux M, Bedenne L, Fabre JM, Saint-Aubert B, Genève J, Lasser P and Rougier P: Perioperative chemotherapy compared with surgery alone for resectable gastroesophageal adenocarcinoma: an FNCLCC and FFCD multicenter phase III trial. J Clin Oncol 29: 1715-1721, 2011. PMID: 21444866 doi: 10.1200/JCO.2010.33.0597

11 Fukuchi M, Mochiki E, Ishiguro T, Kumagai Y, Ishibashi K and Ishida $\mathrm{H}$ : Prognostic significance of conversion surgery following first- or second-line chemotherapy for unresectable gastric cancer. Anticancer Res 38: 6473-6478, 2018. PMID: 30396974 doi: 10.21873 /anticanres. 13010

12 Reddavid R, Sofia S, Chiaro P, Colli F, Trapani R, Esposito L, Solej M and Degiuli M: Neoadjuvant chemotherapy for gastric cancer. Is it a must or a fake? World J Gastroenterol 24: 274289, 2018. PMID: 29375213 doi: 10.3748/wjg.v24.i2.274

13 Miyoshi S, Tsugawa H, Matsuzaki J, Hirata K, Mori H, aya H, Kanai $\mathrm{T}$ and Suzuki H: Inhibiting xCT improves 5-fluorouracil resistance of gastric cancer induced by CD44 variant 9 expression. Anticancer Res 38: 6163-6170, 2018. PMID: 30396933 doi: 10.21873/anticanres.12969

14 Yoshikawa T, Rino Y, Yukawa N, Oshima T, Tsuburaya A and Masuda M: Neoadjuvant chemotherapy for gastric cancer in Japan: a standing position by comparing with adjuvant chemotherapy. Surg Today 44: 11-21, 2014. PMID: 23508452 doi: 10.1007/s00595-013-0529-1

15 Zhou J, Shen J, Seifer BJ, Jiang S, Wang J, Xiong H, Xie L, Wang $\mathrm{L}$ and Sui X: Approaches and genetic determinants in predicting response to neoadjuvant chemotherapy in locally advanced gastric cancer. Oncotarget 8: 30477-30494, 2017.PMID: 27802185 doi: 10.18632/oncotarget.12955

16 Jia S, Cai J. Update on biomarkers in development of antiangiogenic drugs in gastric cancer. Anticancer Res 36: 11111118, 2016 PMID: 26977006

17 Giatromanolaki A, Koukourakis MI, Georgiou I, Kouroupi M and Sivridis E: LC3A, LC3B and Beclin-1 expression in gastric cancer. Anticancer Res 38: 6827-6833, 2018. PMID: 30504397 doi: 10.21873 /anticanres.13056

18 Kim HM, Jeong I, Kim HJ, Kang SK, Kwon WS, Kim TS, Park KH, Jung M, Soong J, Lin SC, Chung HC and Rha SY: Casein kinase 2 inhibitor, CX-4945, as a potential targeted anticancer agent in gastric cancer. Anticancer Res 38: 6171-6180, 2018. PMID: 30396934 doi: 10.21873/anticanres.12970

19 Virgilio E, Balducci G, Mercantini P, Giarnieri E, Giovagnoli MR, Montagnini M, Proietti A, D'Urso R and Cavallini M: Utility of nasogastric tube for medical and surgical oncology of gastric cancer: a prospective institutional study on a new and precious application of an old and economic device. Anticancer Res 38: 433-439, 2018. PMID: 29277806 doi: 10.21873/ anticanres. 12241

20 Virgilio E, Giarnieri E, Montagnini M, D’Urso R, Proietti A, Mesiti A, Giovagnoli MR, Mercantini P, Cavallini M and Balducci G: Analyzing gastric lavage of gastric cancer patients: a prospective 
observational study on cytopathology and determination of intragastric CEA, Ca 19.9, Ca 72.4 and Ca 50. Acta Cytol 60: 161166, 2016. PMID: 27096417 doi: 10.1159/ 000445765

21 Virgilio E, Giarnieri E, Giovagnoli MR, Montagnini M, Proietti A, D’Urso R, Nigri G, Mercantini P, Ramacciato G, Cavallini M and Balducci G: Presence of cancer cells in gastric lavage of gastric cancer patients as an indicator of advanced disease, predictor of tumour aggressive phenotype and independent prognostic factor for poor survival: The endoluminal metastatic pathway of gastric cancer and GL0/GL1 classification. Cytopathology 29: 41-48, 2018. PMID: 29063636 doi: 10.1111/ cyt12484

22 Virgilio E, Giarnieri E, Montagnini M, D’Urso R, Proietti A, Mesiti A, Giovagnoli MR, Mercantini P, Cavallini M and Balducci G: Detection of cancer cells and tumor markers in gastric lavage of patients with gastric cancer: do these findings have a clinicopathological significance and oncological implication? Med Hypotheses 94: 1-3, 2016. PMID: 27515187 doi: 10.1016/j.mehy.2016.06.010

23 Virgilio E, Proietti A, D’Urso R, Cardelli P, Giarnieri E, Montagnini M, Giovagnoli MR, Mercantini P, Balducci G and Cavallini M: Measuring intragastric tumor markers in gastric cancer patients: a systematic literature review on significance and reliability. Anticancer Res 37: 2817-2821, 2017. PMID: 28551616 doi: 10.21873 /anticanres.11632

24 Experts Committee on Cancer -Related Anemia and Chinese society of Clinical Oncology (CSCO): Clinical practice guidelines on cancer-related anemia (2012-2013 Edition). Chin Clin Oncol 1: 18, 2012. PMID: 25841396 doi: 10.3978/ j.ssn.2304-3865.2012.10.01

25 Becker K, Mueller JD, Schulmacher C, Ott K, Fink U, Busch R, Böttcher K, Siewert JR and Höfler H: Histomorphology and grading of regression in gastric carcinoma treated with neoadjuvant chemotherapy. Cancer 98: 1521-1530, 2003. PMID: 14508841 doi: $10.1002 /$ cncr. 11660

26 Edge SB and Compton CC: The American Joint Committee on Cancer: the 7th edition of the AJCC cancer staging manual and the future of TNM. Ann Surg Oncol 17: 1471-1474, 2010. PMID: 20180029 doi: 10.1245/s 10434-010-0985-4

27 Sisic L, Blank S, Nienhüser H, Dorr S, Haag GM, Jäger D, Bruckner T, Müller-Stich BP, Ott K, Büchler MW, Ulrich A and Schmidt T: Prognostic differences in 8th edition TNM staging of esophagogastric adenocarcinoma after neoadjuvant treatment. Eur J Surg Oncol 44: 1646-1656, 2018. PMID: 30082176 doi: 10.1016/j.ejso.2018.06.030

28 Bartsch R, Dubsky PC, Loibl S and Steger G: Opinions on the ASCO 2011 Annual Meeting. Brest Cancer (Basel) 6: 315-319, 2011. PMID: 22164128 doi: $10.1159 / 000331171$

29 Hudis CA, Barlow WE, Constantino JP, Gray RJ, Pritchard KI, Chapman JA, Sparano JA, Hunsberger S, Enos RA, Gelber RD and Zujewski JA: Proposal for standardized definitions for efficacy end points in adjuvant breast cancer trials: the STEEP system. J Clin Oncol 25: 2127-2132, 2007. PMID: 17513820 doi: $10.1200 / \mathrm{JCO} .2006 .10 .3523$

30 Virgilio E, Giarnieri E, Giovagnoli MR, Montagnini M, Proietti A, D’Urso R, Mercantini P, Balducci G and Cavallini M: Early gastric cancer exfoliating into gastric lavage (GL1 EGC) shows a more aggressive behavior and poorer survival compared to the non-exfoliative counterpart (GL0 EGC). Anticancer Res 37: 41994203, 2017. PMID: 28739707 doi: 10.21873/ anticanres.11810
31 Ikoma N, Hofstetter WL, Estrella JS, Das P, Minsky BD, Fournier KF, Mansfield PF, Ajani JA and Badgwell BD: The ypT category does not impact overall survival in node negative gastric cancer. J Surg Oncol 117: 1721-1728, 2018. PMID: 29949666 doi: $10.1002 /$ jso.25081

32 Langer $\mathrm{R}$ and Becker $\mathrm{K}$ : Tumor regression grading of gastrointestinal cancers after neoadjuvant therapy. Virchows Arch 472: 175-186, 2018. PMID: 28918544 doi: 10.1007/s00428-0172232-x

33 Tsekrekos A, Detlefsen S, Riddell R, Conner R, Mastracci L, Sheahan K, Shetye J, Lundell L and Vieth M: Histopathologic tumor regression grading in patients with gastric carcinoma submitted to neoadjuvant treatment: results of a Delphi survey. Hum Pathol, 2018. pii: S0046-8177(18)30354-X. PMID: 30217622 doi: 10.1016/j.humpath.2018.08.028.

34 Belmouhand M, Löfgren J, Johannesen HH, Baeksgaard L, Gutte $\mathrm{H}$, Tariq K, Achiam MP. Early response evaluation of neoadjuvant therapy with PET/MRI to predict respectability in patients with adenocarcinoma of the esophagogastric junction. Abdom Radiol (NY), 2018. PMID. 30467723 doi: 10.1007/s00261-018-1841-4.

35 Cardona K, Zhou Q, Gönen M, Shah MA, Strong VE, Brennan $\mathrm{MF}$ and Coit DG: Role of repeat staging laparoscopy in locoregionally advanced gastric or gastroesophageal cancer after neoadjuvant therapy. Ann Surg Oncol 20: 548-554, 2013. PMID: 22941159 doi: 10.1245/s10434-012-2598-6

36 Sun Z, Zhang N: Clinical evaluation of CEA, CA19-9, CA72-4 and $\mathrm{CA} 125$ in gastric cancer patients with neoadjuvant chemotherapy. World J Surg Oncol 12: 397, 2014. PMID: 25543664 doi: 10.1186/1477-7819-12-397

37 Cao Y, Chang Q, Cabanero M, Zhang W, Hafezi-Bakhtiari S, Hedley D, Darling G, Quereshy F, Jang R, Elimova E, Knox J, Ornatsky O, Serra S, Chen E. Tumor platinum concentrations and pathological responses following cisplatin-containing chemotherapy in gastric cancer patients. J Gastrointest Cancer, 2018. PMID: 30117091 doi: 10.1007/s12029-018-0153-9.

38 Li S, Li B, Wang J, Zhang D, Liu Z, Zhang Z, Zhang W, Wang Y, Bai D, Guan J and Zhang Y: Identification of sensitivity predictors of neoadjuvant chemotherapy for the treatment of adenocarcinoma of gastroesophageal junction. Oncol Res 25: 9397, 2017. PMID: 28081737 doi: 10.3727/096504016X147 19078133564

39 Bozkaya Y, Özdemir NY, Sezer S, Köstek O, Demirci NS, Yazıc1 O, Erdem GU, Eren T, Zengin N. Is serum survivin expression a predictive biomarker in locally advanced cancer patients treated with neoadjuvant chemotherapy? Cancer Biomark 22: 143-149, 2018. PMID: 29562501 doi: 10.3233/CBM-171119

40 Tan B, Li Y, Di Y, Fan L, Zhao Q, Liu Q, Wang D and Jia N: Clinical value of peripheral blood microRNA detection in evaluation of SOX regimen as neoadjuvant chemotherapy for gastric cancer. J Clin Lab Anal 32: e22363, 2018. PMID: 29168576 doi: 10.1002/jcla.22363.

41 Kon OL, Yip TT, Ho MF, Chan WH, Wong WK, Tan SY, Ng WH, Kam SY, Eng AKh, Ho P, Viner R, Ong HS and Kumarasinghe MP: The distinctive gastric fluid proteome in gastric cancer reveals a multi-biomarker diagnostic profile. BMC Med Genomics 1: 54, 2008. PMID: 18950519 doi: 10.1186/1755-8794-1-54

42 Virgilio E, Balducci G, Mercantini P, Giarnieri E, Giovagnoli MR, Montgnini M, Proietti M, D’Urso R and Cavallini M: Preoperative gastric lavage in gastric cancer patients undergoing 
surgical, endoscopic or minimally invasive treatment: an oncological measure preventing peritoneal spillage of intragastric cancer cells and development of related metastases. Med Hypotheses 114: 30-34, 2018. PMID: 29602460 doi: 10.1016/j.mehy.2018.02.023

43 Virgilio E, Giarnieri E, Giovagnoli MR, Montagnini M, Proietti A, D'Urso R, Mercantini P, Balducci G and Cavallini M: Gastric juice microRNAs as potential biomarkers for screening gastric cancer: a systematic review. Anticancer Res 38: 613-616, 2018. PMID: 29374683 doi: 10.21873/anticanres.12265

44 Virgilio E, Giarnieri E, Giovagnoli MR, Montagnini M, Proietti A, D’Urso R, Mercantini P, Balducci G and Cavallini M: Long non-coding RNAs in the gastric juice of gastric cancer patients Pathol Res Pract 214: 1239-1246, 2018. PMID: 30078471 doi: 10.1016/j.prp.2018.07.023

45 Sato S, Kunisaki C, Tanaka Y, Sato K, Miyamoto H, Yukawa N, Gujii Y, Kimura J, Takagawa R, Takahashi M, Kosaka T, Akiyama H, Saigusa Y, Taguri M, Yamanaka T and Endo I: A phase II study of tri-weekly low-dose Nab-paclitaxel chemotherapy for patients with advanced gastric cancer. Anticancer Res 38: 6911-6917, 2018. PMID: 30504409 doi: 10.21873/anticanres.13068

46 Liu X, Qiu H, Huang Y, Xu D, Li W, Li Y, Chen Y, Zhou Z and Sun $X$ : Impact of preoperative anemia on outcomes in patients undergoing curative resection for gastric cancer: a singleinstitution retrospective analysis of 2163 Chinese patients. Cancer Med 7: 360-369, 2018. PMID: 29341506 doi: 10.1002/ cam4.1309
47 Reim D, Kim Y-W, Nam BH, Kim MJ, Yook JH, Park YK, Roh $\mathrm{SH}, \mathrm{Yu}$ WS and Bae JM: FAIRY: a randomized controlled patient-blind phase III study to compare the efficacy and safety of intravenous ferric carboxymaltose (Ferinject ${ }^{\circledR}$ ) to placebo in patients with acute isovolemic anemia after gastrectomy - study protocol for a randomized controlled trial. Trials 15: 111, 2014. PMID: 24708660 doi: 10.1186/1745-6215-15-111.

48 Abbrederis K, Bassermann F, Schuhmacher C, Voelter V, Busch R, Roethling N, Sendler A, Siewert JR, Peschel C and Lordick F: Erythropoietin-alfa during neoadjuvant chemotherapy for locally advanced esophagogastric adenocarcinoma. Ann Thorac Surg 82: 293-297, 2006. PMID: 16798232 doi: 10.1016/ j.athoracsur.2006.01.097

49 Voelter V, Schuhmacher C, Busch R, Peschel C, Siewert JR and Lordick F: Incidence of anemia in patients receiving neoadjuvant chemotherapy for locally advanced esophagogastric cancer. Ann Thorac Surg 78: 1037-1041, 2004. PMID: 15337044 doi: 10.1016/j.athoracsur.2004.01.049

Received December 25, 2018

Revised January 17, 2019

Accepted January 22, 2019 